\title{
Slurry Phase Hydrocracking of Residue by Phosphomolybdic and Phosphotungstic Acids \\ Prajapati $\mathbf{R}^{*}$, Kohli K, Maity SK and Garg MO \\ CSIR-Indian Institute of Petroleum, Dehradun- 248005, India
}

\begin{abstract}
Slurry phase hydrocracking of vacuum residue was studied on heteropoly acids and on super acid. In this regards, heteropoly acid of phosphomolybdic, phosphotungstic and superacid of molybdenum-antimony fluoride were used. Deep hydrocracking of residue was noticed even at moderate operating conditions for all acidic catalysts. Due to higher hydrogenating functionality of tungsten, the HDM activity of the phosphotungstic acid is higher than that of molybdenum containing acids. Even the residue hydrocracking activity of former catalyst is also high. It is also noticed from sulphur distribution of liquid product that thiophenic sulphur compounds are formed due to C-S bond cleavage at branching of condensed aromatic rings. Moreover, phosphotungstic acid gives high percentage of aromatic products whereas the considerable amount of saturate hydrocarbons is produced by phosphomolybdic acid. The coke produced by phosphotungstic acid catalyst is hard in nature indicating that extensive polymerization reaction occurs at reaction conditions. Higher $\mathrm{H} / \mathrm{C}$ ratio indicates the deep hydrogenation of liquid products in presence of super acids. Instead of use superacid, tungsten based heteropoly acid can be effectively used for hydrocracking of residue.
\end{abstract}

Keywords: Superacid; Heteropoly acid; Residue conversion; Slurry phase; FT-IR; TGA

\section{Introduction}

The future demand of transportation fuel can be fulfilled by upgrading unconventional reserves of heavy oil [1]. The amount of extra-heavy oil and bitumen is predicted to be around 5.4 trillion barrels. This heavy oil and bitumen contain high concentrations of heteroatoms like sulphur, nitrogen, carbon residue and metal contents like Ni, V. Due to the presence of high percentage of carbon residue, hydrocracking of heavy oils and their residue is challenging for refiners. In this respect, the acid functionality of a catalyst has an important role for residue hydrocracking. In a conventional supported catalyst, Lewis acid sites are used. In a typical catalyst system, metals like Mo, W, Ni, and Co are impregnated on acidic support like alumina; alumina based mixed oxide, modified zeolite and other support having acid sites [2-5]. However these supported catalysts are deactivated rapidly due to pore plugging by metal, and coke. Moreover, the coke deposit increases with increasing the acidity of the supported catalyst. The rapid deactivation of the supported catalyst can be avoided if unsupported catalyst is used in slurry phase hydrocracking. Heteropoly acid is an alternative of acidic supported catalyst for residue hydrocracking. Sometimes, this super solid acid is modified by active metals like, Mo and W to increase the hydrogenation functionality. The hydrogenation functionality reduces coke formation during hydrocracking reaction.

Hydrocracking activity of phosphotungstic acid was compared with a conventional NiMo supported catalyst [6]. Cs exchange on the acidic catalyst was made to obtain appropriate physicochemical property of the catalyst. Compared with a conventional catalyst, higher hydrocracking activity of Cs-phosphotungstic catalyst was reported. Moreover, the removal of metals and sulphur of acidic catalyst was also comparable with the supported catalyst. For coal liquefaction, Olah et al. [7-9] extensively used superacid. Authors have shown that $\mathrm{HBF}_{4}$ based superacid could be good catalyst for conversion of tar sand. The depolymerisation of coal took place during hydroliquefaction reaction. The product had more than $90 \%$ pyridine solubility indicating the higher conversion of coal to lighter hydrocarbons. It was also reported that in the presence of acidic environment, comparatively less temperature was required. A highly reactive superacid like ethyl fluoride: antimony pentafluoride complex are used for alkylation reaction of coal [9]. It was also reported by others $[10,11]$ that superacids can be prepared by metal halides with anhydrous HF and their hydrocracking activity was tested. Hydrocracking activity of tar sand bitumen and asphaltene by HR.BF $\mathrm{B}_{3}$ superacid was also studied by Strausz et al. [12]. It was reported that this superacid was very effective for both aliphatic and aromatic feedstock for hydrocracking even at mild experimental conditions. It was also mentioned that this superacid could be used for oligomerization of cycloalkanes. Wen et al. [13] used solid super acid for hydroisomerisation of heptanes and hexadecane. The acidic functionality containing Mo and $\mathrm{W}$ has been shown to be superior to conventional amorphous catalysts with respects to acidity, selectivity and resistance to poison. Gates and co-workers [14,15] used polymer superacid resins for isomerisation and cracking of paraffins. Polymeric super acid are more feasible to protonate olefins which leads to isomerisation followed by carbonium ion and hydride rearrangement. Imamura et al. [16-18] used brominated intermettalic compounds for isomerisation of pentane metal oxides. The following materials $\mathrm{LaAl}_{2}, \mathrm{CeAl}_{2}, \mathrm{PrAl}_{2}, \mathrm{ErAl}_{2}, \mathrm{SmAl}$, and $\mathrm{ThAl}_{2}$ were used for formation of intermettalics. Hattori et al. [19] prepared various types solid superacid by treating metal oxides with $\mathrm{NH}_{4} \mathrm{~F}, \mathrm{FSO}_{3} \mathrm{H}, \mathrm{SbCl}_{5}, \mathrm{SbF}_{5}$, and $\mathrm{FSO}_{3} \mathrm{H}_{-} \mathrm{SbF}_{5}$. The author observed that $\mathrm{SbF}_{5}$ was better among all above superacid for paraffins conversion. Even high conversion could be achieved at lower reaction temperature.

In this present work phosphomolybdic and phosphotungstic acids were prepared and their residue hydrocracking activities were

"Corresponding author: Prajapati R, CSIR-Indian Institute of Petroleum, Dehradun- 248005, India, Tel: +91-135-2525724; E-mail: ravindrap@iip.res.in

Receive June 06, 2016; Accepted June 22, 2016; Published June 30, 2016

Citation: Prajapati R, Kohli K, Maity SK, Garg MO (2016) Slurry Phase Hydrocracking of Residue by Phosphomolybdic and Phosphotungstic Acids. J Pet Environ Biotechnol 7: 281. doi:10.4172/2157-7463.1000281

Copyright: (c) 2016 Prajapati $\mathrm{R}$, et al. This is an open-access article distributed under the terms of the Creative Commons Attribution License, which permits unrestricted use, distribution, and reproduction in any medium, provided the original author and source are credited. 
compared with MoSbF superacid. These catalysts were used for slurry phase reaction in a batch reactor at moderate reaction conditions. The effect of acid catalysts on the distribution of product has been studied. The characterisation of liquid and solid products was carried out using various techniques and correlations were made.

\section{Experimental}

\section{Catalyst preparation}

Three acidic catalysts phosphomolybdic acid, phosphotungstic acid and molybdenum-antimony fluoride superacid were used in this work. For the preparation of phosphomolybdic catalyst, $\mathrm{MoO}_{3}$ was prepared first by heating of ammonium heptamolybdate tetrahydrate (AHM) in SS tubular reactor at $450^{\circ} \mathrm{C}$ in presence of air for four hours. Molybdenum oxide was mixed with phosphoric acid and water in round bottle flask. The mixture was heated up to 4 hours and then filtered. During heating, the mixture becomes milky solution and then it changes to yellow with increasing temperature. The filtrate solution was boiled at $110^{\circ} \mathrm{C}$ and then cooled down so that crystallisation took place. The deep yellow crystals were obtained after drying in vacuum oven.

For preparation of phosphotungstic acid, $\mathrm{Na}_{2} \mathrm{WO}_{4} \cdot 2 \mathrm{H}_{2} \mathrm{O}$ was mixed with phosphoric acid and water in a round bottle flask. The mixture was heated. The acidification took place by addition of $\mathrm{HCl}$. On the increasing temperature, the mixture colour changes to greyish colour. The mixture was heated up to 3 hours and then filtered. The filtrate solution was boiled at $110^{\circ} \mathrm{C}$ and then cooled down so that crystallisation takes place. The deep yellow-green crystals were obtained after drying in vacuum oven.

Mo based $\mathrm{SbF}_{5}$ super acid catalyst was prepared in high pressure and high temperature reactor. Solution of ammonium heptamolybdate was mixed with of $\mathrm{SbF}_{5}$. The mixture was taken in a batch reactor and the reactor was pressurised by nitrogen. The mixture was heated to $180^{\circ} \mathrm{C}$ for 90 minutes. The reactor was cooled down and mixture was filtered with glass-wool. Flow diagram for the synthesis of three acid catalysts is described in Figure 1. The above prepared catalysts, phosphomolybdic, phosphotungstic and molybdenum-antimony fluoride acids are designated as $\mathrm{H}_{3} \mathrm{PMo}, \mathrm{H}_{3} \mathrm{PW}$ and MoSbF respectively.

\section{Catalyst activity test}

The catalyst was tested in a high pressure and high temperature batch reactor. Before actual test run, the catalyst was sulphided in-situ. For this, the catalyst (aqueous solution) was taken with $200 \mathrm{gm}$ of feed which has very high concentration of sulphur. The reactor vessel was sealed properly and checked for leakage. The reactor vessel was then purged two/three times with hydrogen gas, so that there was no air left inside the reactor. An appropriate amount of hydrogen was added into the reactor so that the final pressure can reached to $100 \mathrm{~kg} / \mathrm{cm}^{2}$ at reaction temperature. Heating was started from room temperature
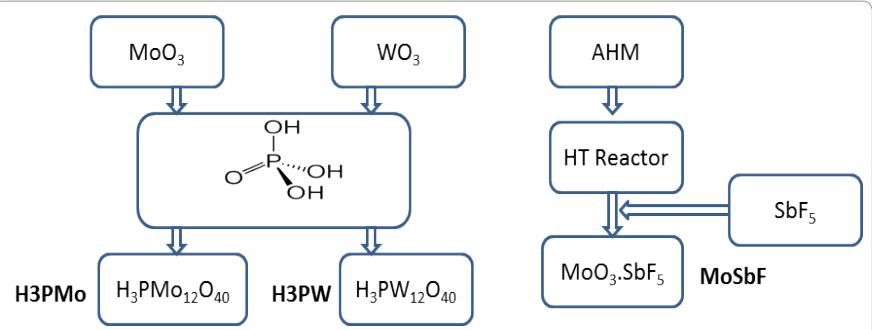

Figure 1: Flow diagram of catalysts preparation.

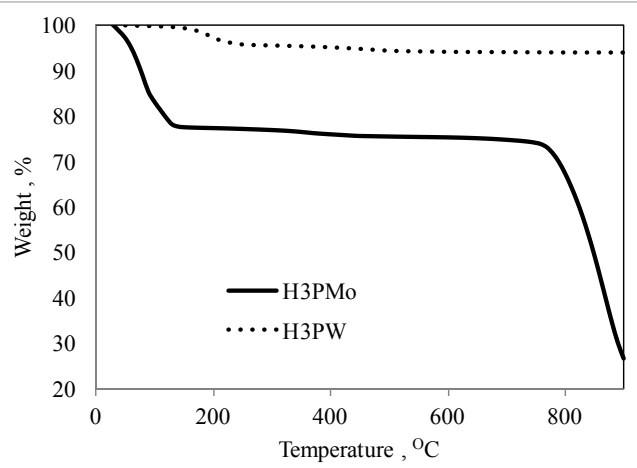

Figure 2: Thermal stability of phosphomolybdic and phosphotungstic acids.

to $350^{\circ} \mathrm{C}$ at the rate of $3^{\circ} \mathrm{C} / \mathrm{min}$. The sulphidation was performed in presence of high sulphur feed for 30 minutes.

After completion of sulphidation, the reaction temperature was increased to $410^{\circ} \mathrm{C}$ at the rate of $3^{\circ} \mathrm{C} / \mathrm{min}$. Stirring was started when temperature reached the set point (reaction temperature) and the time was noted as the beginning of the reaction. The experimental conditions for batch reactor are: reaction temperature, $410^{\circ} \mathrm{C}$; reaction pressure, $100 \mathrm{~cm}^{2} / \mathrm{kg}$; total reaction time, $4 \mathrm{~h}$ and stirring rate, $750 \mathrm{rpm}$. After the reaction liquid products were then separated from solid material. The residue conversion for this study was calculated by using the following equation.

$$
\begin{aligned}
& \text { Residue Conversion }= \\
& \frac{\left(550^{\circ} \mathrm{C}+\text { in feed }-550^{\circ} \mathrm{C}+\text { in product }\right)}{\left(550^{\circ} \mathrm{C}+\text { in feed }\right)} \times 100
\end{aligned}
$$

\section{Analysis of feed and products}

Feed and hydrotreated liquid products were characterised by various techniques like, metal content using ICP-AES (Leeman Model DRE, PS-3000UV), sulphur content with Oxford sulphur analyzer (Lab-X 3500) and CHNS analysis using Elementar Vario Micro CHNS analyzer. ASTM D-4124-09 was used for SARA analysis. Coke was extracted from solid material by soxhlet method using toluene as solvent. Sulphur distribution of the liquid products was also analysed by GC using PFPD as sulphur specific detector. UV (model Shidmazu-2600) and FT-IR (model Nicolet-87000) techniques were also used to analyse the liquid products. These two techniques were also used to characterise the solid coke and catalyst respectively. XRD and TGA (model Perkin Elmer - 4000) were used to characterise the solid coke. TGA analysis was performed in the flow of air by heating the catalyst sample from room temperature to $900^{\circ} \mathrm{C}$ at the rate of $10^{\circ} \mathrm{C} /$ min. Product distribution of hydrotreated liquid was measured by TGA analysis. The details experiment procedure was given elsewhere [20,21].

\section{Results and Discussion}

\section{Catalyst characterization}

Thermal stability of two catalysts was measured by TGA and the results are presented in Figure 2. TGA curves show two distinctive characteristic of these two catalysts. Initial weight loss of $\mathrm{H}_{3} \mathrm{PMo}$ catalyst is due to the water loss and around $22 \mathrm{wt} \%$ of weight loss is observed. It is worth to mention that total water was not removed during crystallization of this catalyst. After initial weight loss, the catalyst shows a stable form upto around $775^{\circ} \mathrm{C}$ temperature. Above this temperature, sharp weight loss of this catalyst is noticed. However, 
the catalyst having tungsten shows stability with respect to temperature. Only around $4 \mathrm{wt} \%$ of weight loss is observed. Thermal stability of both molybdenum and tungsten based heteropolyacids were studied by Okuhara et al. [22]. The presence of two types of water- crystallization water and constitutional water was reported. The crystallization water is lost at lower temperature below $200^{\circ} \mathrm{C}$ whereas for the removal of constitutional water requires higher temperature. It was also reported that constitutional water is strongly attached with tungsten heteropolyacid and removal of it requires much higher temperature. Very minor loss of water during heating of phosphotungstic acid was also observed by other [6]. Overall TGA results show that phosphotungstic acid is thermally very stable compared with that of phosphomolybdic acid. Therefore no catalyst degradation or rearrangement is expected during actual hydroprocessing reaction conditions.

To characterize functional groups present in catalysts, Fourier transform infra red (FT-IR) spectroscopy was used. Both $\mathrm{H}_{3} \mathrm{PMo}$ and $\mathrm{H}_{3} \mathrm{PW}$ catalysts show very different FT-IR transmittance as shown in Figure 3. IR spectrogram of $\mathrm{H}_{3} \mathrm{PMo}$ catalyst reveals $\mathrm{OH}$ stretching and $\mathrm{OH}$ bending frequencies at around 2900 and $1415 \mathrm{~cm}^{-1}$ respectively. However, $\mathrm{H}_{3} \mathrm{PW}$ shows four absorption peaks of $\mathrm{P}-\mathrm{O}, \mathrm{W}-\mathrm{O}, \mathrm{W}-\mathrm{O}-\mathrm{W}$ (on plane) and W-O-W (out plane) at 1080, 981, 888 and $806 \mathrm{~cm}^{-1}$ respectively. These are characteristics peaks for phosphotungstic acid [23].

\section{Hydroprocessing activities}

Hydro-processing activities like hydro-desulfurization (HDS), hydro-demetallization (HDM), and asphaltene conversion (HDAs) of the prepared catalysts have been performed in the batch reactor. Vacuum residue having $5.45 \mathrm{wt} \%$ sulphur and $305 \mathrm{wppm}$ of metals was used as feed for this study. The detailed characteristics of this feed are given in Table 1 . Table also shows that this feed is highly viscous material and contains very high amount of microcarbon residue. This

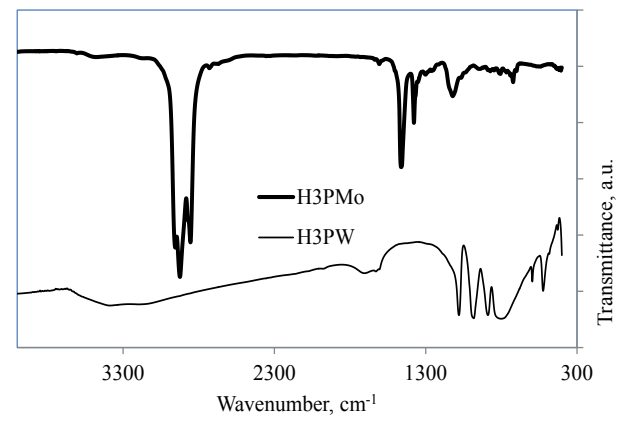

Figure 3: FT-IR spectra of phosphomolybdic and phosphotungstic acids.

\begin{tabular}{|c|c|}
\hline Properties & Value \\
\hline Density @15.6º (g/mL) & 1.05 \\
\hline $\mathrm{K}_{\mathrm{vis}} @ 100^{\circ} \mathrm{C}(\mathrm{cSt})$ & 25794 \\
\hline$@ 135^{\circ} \mathrm{C}(\mathrm{cSt})$ & 1513 \\
\hline $\mathrm{H} / \mathrm{C}$ (atomic) & 01.07 \\
\hline $\mathrm{S}(\mathrm{wt} \%)$ & 5.45 \\
\hline $\mathrm{N}($ wt \%) & 0.87 \\
\hline $\mathrm{Ni}$ (wppm) & 65.00 \\
\hline V (wppm) & 240.00 \\
\hline Saturate (wt \%) & 8.89 \\
\hline Aromatic (wt \%) & 25.88 \\
\hline Resin (wt \%) & 43.25 \\
\hline Asphaltene (wt \%) & 21.98 \\
\hline MCR (wt \%) & 27.26 \\
\hline
\end{tabular}

Table 1: Characteristics of feed.

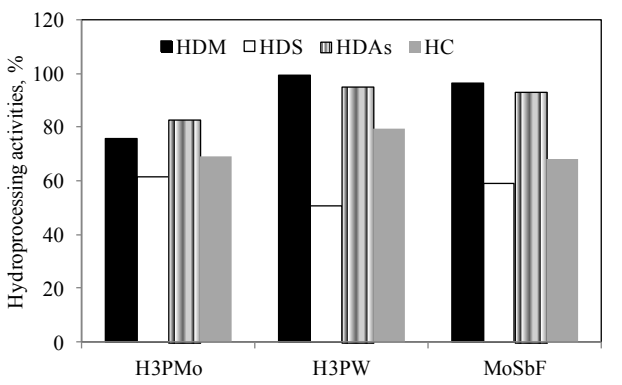

Figure 4: Hydroprocessing activities of three acidic catalysts.

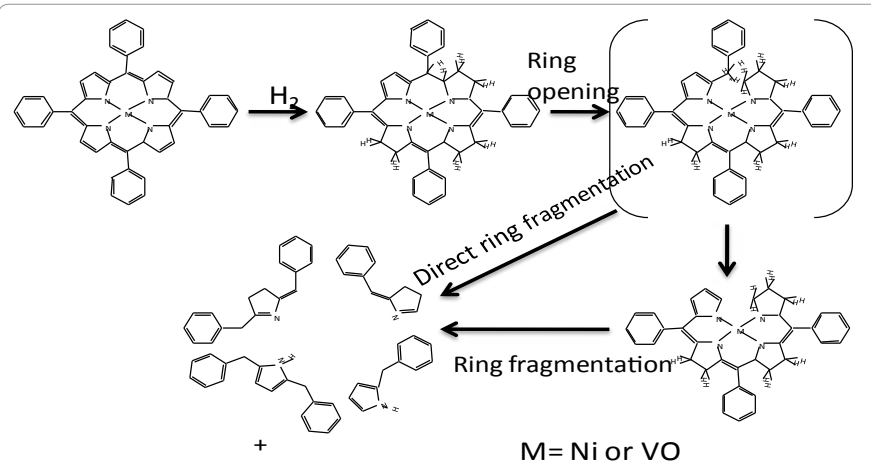

Metal sulfide deposit

Figure 5: Mechanism of metals removal from porphyrin ring by hydrogenation route (1).

microcarbon residue has very detrimental effect due to its very high coke formation tendency during hydroprocessing reaction. It could be very difficult to hydrocrack this residue by conventional supported catalyst. In Figure 4, HDS, HDM and HDAs of three catalysts have been compared. The catalyst, phosphotungstic acid, gives the highest HDM and HDAs activities. Though the HDM and HDAs activities of $\mathrm{H}_{3}$ PMo catalyst are less but it shows the slightly higher HDS activity.

Table 1 shows that feed contains very high percentage of metals mostly in the form of nickel and vanadium. These two metals in the feed are in the form of porphyrin and non porphyrin structure. The porphyrin structure is well characterised whereas non porphyrin structure is less characterised. The metals in non porphyrin structure may be associated with nitrogen, oxygen and sulphur in the defect centres of asphaltene molecule. The mechanism of metal removal from porphyrin ring is presented in Figure 5. Hydrogenation of aromatic ring is necessary so that a catalyst can contact with metal atom before its removal from feed. It is well documented in the literature [24-26] that tungsten has higher hydrogenating functionality compared with that of molybdenum. Therefore, the HDM activity of phosphotungstic acid is higher than that of phosphomolybdic acid. In general asphaltene conversion follows like HDM activity and that why this catalyst also shows higher HDAs conversion. This comparison is particularly relevant for $\mathrm{H}_{3} \mathrm{PMo}$ and $\mathrm{H}_{3} \mathrm{PW}$ heteropoly acids. Due to strong acidity, MoSbF also shows high HDM and HDAs activity.

To investigate more deeply to the hydro-desulfurization activity, the sulphur distribution in the liquid products is determined by GC and it is given in Figure 6. Presence of mostly sulphur compounds like benzo-thiophene (BT) and its derivatives are observed. Due to deep cracking by $\mathrm{H}_{3} \mathrm{PW}$ catalyst, thiophenic sulphur compounds in low concentration are also noticed at lower RT. These thiophenic sulphur compounds may be produced by cracking of resins or asphaltene having 

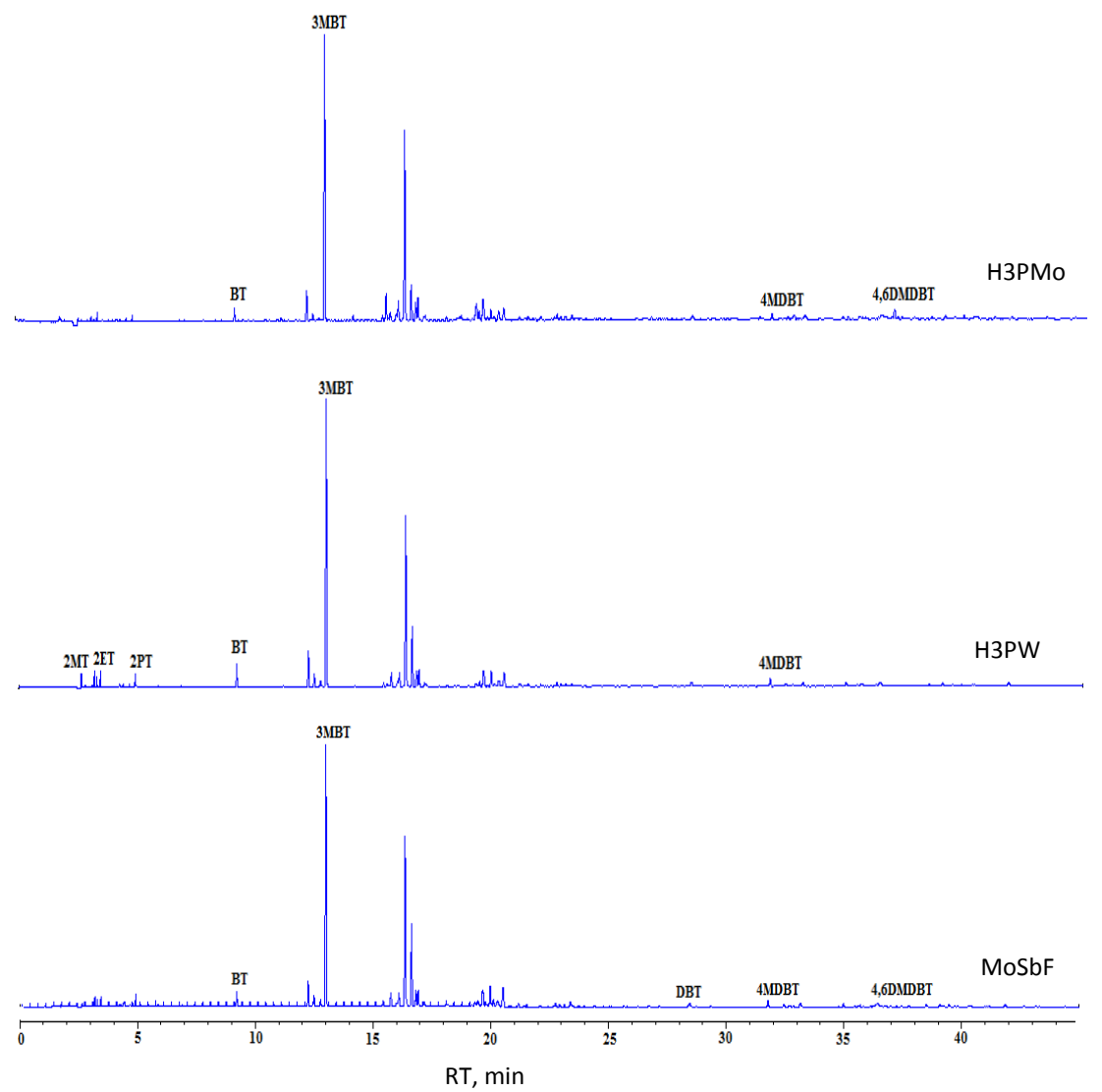

Figure 6: Sulphur distributions in liquid products.

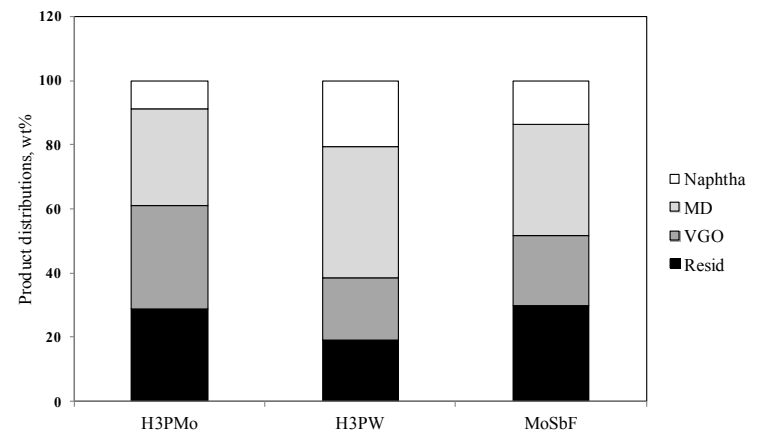

Figure 7: Product distributions in liquid products.

thiophenic sulphur compounds in branching. And therefore, the coke produced by this catalyst has slightly lower concentration of sulphur (discuss later). Presence of refractory sulphur compounds like dibenzothiophene (DBT) and its derivatives (4-MDBT and 4,6-DMDBT) is very negligible. So the sulphur distribution suggests that during the cracking reaction of vacuum residue $\left(550^{\circ} \mathrm{C}+\right.$ hydrocarbons), the sulphur compounds having one benzene ring are mostly produced by heteropolyacids or super acid catalysts.

The main objective of residue upgradation is its conversion into the lighter fractions. The residue conversion (HC) of the three catalysts was calculated and the results are compared in Figure 4. The residue conversions of molybdenum based catalysts i.e., $\mathrm{H}_{3} \mathrm{PMo}$ and $\mathrm{MoSbF}$ are almost same whereas catalyst $\mathrm{H}_{3} \mathrm{PW}$ also shows the highest residue conversion. Though, the cracking activity in slurry phase reaction is mostly thermally controlled, but acidity and hydrogen functionally may facilitate this cracking activity. As it is mention that tungsten has comparatively high hydrogenation activity and therefore, this catalyst can easily hydrogenate aromatic rings before $\mathrm{C}-\mathrm{C}$ bond cleavage. The product distributions obtained by these three catalysts have also been compared in Figure 7. This figure also shows that phosphotungstic acid produces higher percentage of lighter products like naphtha $\left(<150^{\circ} \mathrm{C}\right)$ and middle distillate $\left(\mathrm{MD}, 150-350^{\circ} \mathrm{C}\right)$ in expense of residue and VGO. The productions of middle distillate and vacuum gas Oil (VGO) for $\mathrm{H}_{3}$ PMo catalyst are almost same whereas middle distillate is higher than VGO in MoSbF catalyst. The handling of fluoride based MoSbF is quite difficult. Therefore, the use of tungsten containing heteropoly acid could be attractive option for hydrocracking of residue.

\section{Characteristics of liquid products}

During hydrocracking of vacuum residue at elevated temperature and pressure the large hydrocarbons are cracked to lighter hydrocarbons. The different properties of the liquid products are given in Table 2. Table shows that densities, kinematic viscosity, $\mathrm{H} / \mathrm{C}$ ratio, of liquid products are very low compared with the feed. The MCR value of the feed is $27.26 \mathrm{wt} \%$ and it reduces to $4 \mathrm{wt} \%$ in $\mathrm{H}_{3} \mathrm{PW}$ catalyst. SARA analysis was also performed in liquid products. Table shows that resin content in liquid products obtained by catalysts $\mathrm{H}_{3} \mathrm{PW}$ and MoSbF is very low; whereas the saturate in $\mathrm{H}_{3} \mathrm{PMo}$ is high. The $\mathrm{H} / \mathrm{C}$ ratio of liquid product also indicates the hydrogenation of the feed in the presence of acid catalysts. More hydrogenation of feed in $\mathrm{H}_{3} \mathrm{PW}$ is also noticed from the higher value of $\mathrm{H} / \mathrm{C}$. 
UV visible spectrogram of liquid products is demonstrated in Figure 8. The bathochromic shift (red shift or spectra at longer wavelength) in UV spectra is an indication for the presence of aromatics. The red shift present in UV spectrogram reveals that $\mathrm{W}$ based heteropoly acid produce comparatively larger amount of aromatic compounds which is also observed in our SARA analysis.

The functional groups present in the liquid products are also measured by FT-IR and the results are given in Figure 9. The products of all catalysts show almost similar pattern indicating of having similar kinds of functional groups. In this figure, $\mathrm{CH}$ stretching for saturate at $2924 \mathrm{~cm}^{-1}$, and $2854 \mathrm{~cm}^{-1}, \mathrm{C}=\mathrm{C}$ stretching in 5 ring at $1603 \mathrm{~cm}^{-1}$, $\mathrm{CH}_{2}, \mathrm{CH}_{3}$ bending at 1463 and $1377 \mathrm{~cm}^{-1}$, and $\mathrm{CH}$ out of plane bending

\begin{tabular}{|c|c|c|c|}
\hline Properties & $\mathbf{H}_{3} \mathbf{P M o}$ & $\mathbf{H}_{3} \mathbf{P W}$ & MoSbF \\
\hline Density @15.6 ${ }^{\circ} \mathrm{C}(\mathrm{g} / \mathrm{mL})$ & 0.9334 & 0.884 & 0.9094 \\
\hline $\mathrm{K}_{\text {vis }} @ 15.6^{\circ} \mathrm{C}(\mathrm{cSt})$ & 38.83 & 3.14 & 11.14 \\
\hline $\mathrm{H} / \mathrm{C}$ (atomic) & 1.54 & 1.59 & 1.53 \\
\hline Saturate (wt \%) & 32.93 & 13.46 & 14.68 \\
\hline Aromatic (wt \%) & 30.56 & 82.89 & 79.85 \\
\hline Resin (wt \%) & 32.34 & 1.46 & 2.64 \\
\hline Asphaltene (wt \%) & 4.17 & 2.19 & 2.83 \\
\hline MCR (wt \%) & 10.36 & 4.01 & 7.937 \\
\hline Refractive index $\left(20^{\circ} \mathrm{C}\right)$ & 1.6545 & 1.6495 & 1.6507 \\
\hline
\end{tabular}

Table 2: Characteristics of liquid products.

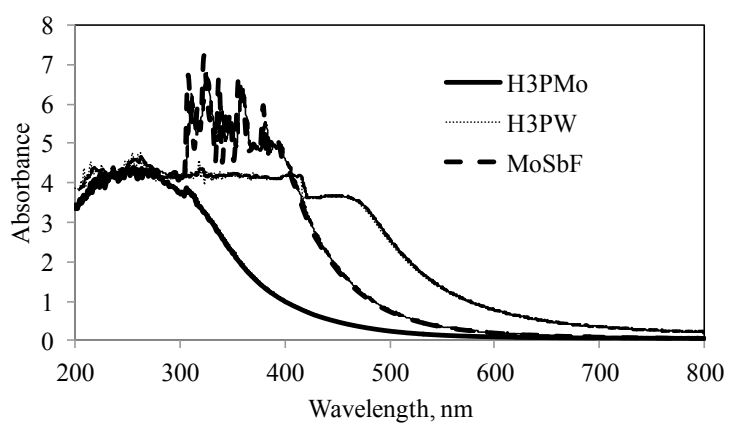

Figure 8: UV spectra of three liquid products.

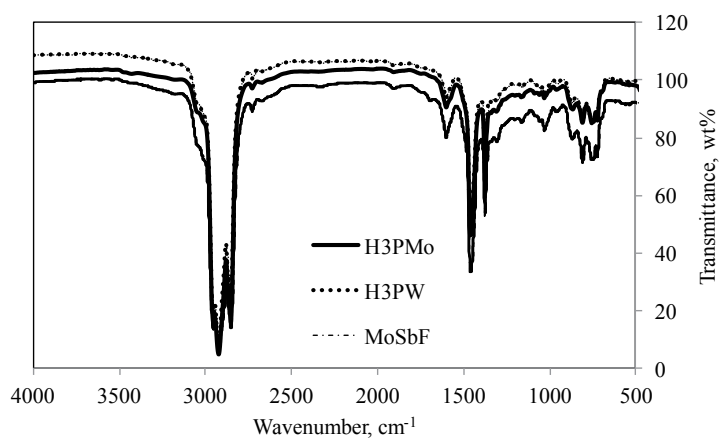

Figure 9: FT-IR spectra of liquid products.

\begin{tabular}{|c|c|c|c|}
\hline Properties & $\mathbf{H}_{3} \mathbf{P M o}$ & $\mathbf{H}_{3} \mathbf{P W}$ & MoSbF \\
\hline H/C (atomic) & 0.73 & 0.78 & 0.73 \\
\hline $\mathrm{N}$ (wt \%) & 1.74 & 1.39 & 1.49 \\
\hline S (wt \%) & 7.48 & 7.33 & 7.61 \\
\hline Ni (wppm) & 643 & 441 & 498 \\
\hline V (wppm) & 1318 & 833 & 799 \\
\hline
\end{tabular}

Table 3: Characteristics of solid cokes.

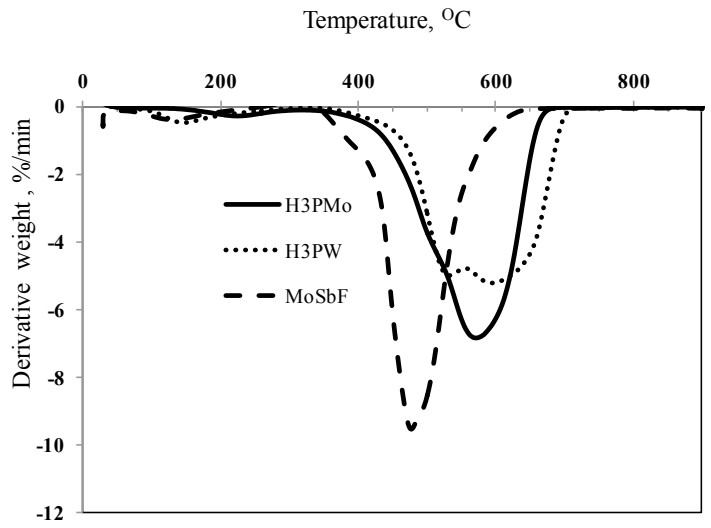

Figure 10: TGA curves of three solid cokes

for substituted benzene at $878 \mathrm{~cm}^{-1}$ transmission peaks are observed [27]. FT-IR results also support that no olefinic hydrocarbon is produced during reaction in presence of acid catalysts. AlHumaidan et al. [28] recently used FT-IR technique for detailed characterization of asphaltenes. The major IR peaks were found due to the saturated hydrocarbons as it was also observed in this study. All other peaks due to $\mathrm{C}=\mathrm{C}$ stretching in aromatic ring, $\mathrm{CH}$ out of plane bending for aromatic were also noticed by authors. Only difference is the presence of strong aromatic C-H stretching at $3150-3000 \mathrm{~cm}^{-1}$ which is very weak in this work. This difference is very obvious. The authors used asphaltene which is highly aromatic in nature whereas hydrotreated liquid products were analysed in this work. These products contain very negligible amount of asphaltene.

\section{Characterization of coke}

The solid product obtained after hydrocracking reaction was separated into asphaltene and coke using soxhlet extraction. The insoluble part in toluene is considered as coke. Nitrogen, sulphur and $\mathrm{H} / \mathrm{C}$ ratio in coke were measured by CHNS analyser and the values are given in Table 3. In this table, metals in coke are also mentioned. $\mathrm{H} / \mathrm{C}$ ratio of coke is low and it is around 0.73 indicating the presence of condensed aromatic rings. Difference of $\mathrm{H} / \mathrm{C}$ ratio of feed, liquid product and coke is noticeable. The $\mathrm{H} / \mathrm{C}$ ratio of feed is 1.07 , whereas it is 1.59 for liquid product and 0.78 for coke obtained by $\mathrm{H}_{3} \mathrm{PW}$ catalyst. Sulphur content in coke produced by this catalyst is lower than that of cokes produced by other two catalysts. It is mentioned earlier that it may be due to the removal of thiophenic sulphur compounds from condensed aromatic side chains. Due to lower hydrodemetallization conversion of $\mathrm{H}_{3} \mathrm{PMo}$ catalyst, more metals are present in the coke.

The hardness property of coke formed during hydrocracking reaction in presence of acid catalyst was determined by TGA analysis. The derivative of weight loss with temperature is reported in Figure 10. All derivative curves show a single weight loss. The maxima of weight loss of coke obtained by MoSbF catalyst is near $480^{\circ} \mathrm{C}$, whereas it is shifted to higher temperature region for the coke obtained by phosphomolybdic and phosphotungstic acids and it is $570^{\circ} \mathrm{C}$ for $\mathrm{H}_{3} \mathrm{PMo}$ and $600^{\circ} \mathrm{C}$ for $\mathrm{H}_{3} \mathrm{PW}$. Moreover, derivative curves for these two catalysts are comparative broad in nature. The nature of derivative curve for $\mathrm{H}_{3} \mathrm{PW}$ is complex and it is superimposed of two curves. Even it is also noticed that the end of burning of coke is around $650^{\circ} \mathrm{C}$ for $\mathrm{MoSbF}$ whereas it is further shifted to higher temperature region for $\mathrm{H}_{3} \mathrm{PMo}$ and $\mathrm{H}_{3} \mathrm{PW}$ catalysts. It indicates that the coke is formed by MoSbF catalyst is soft in nature whereas the coke formed by the catalyst 


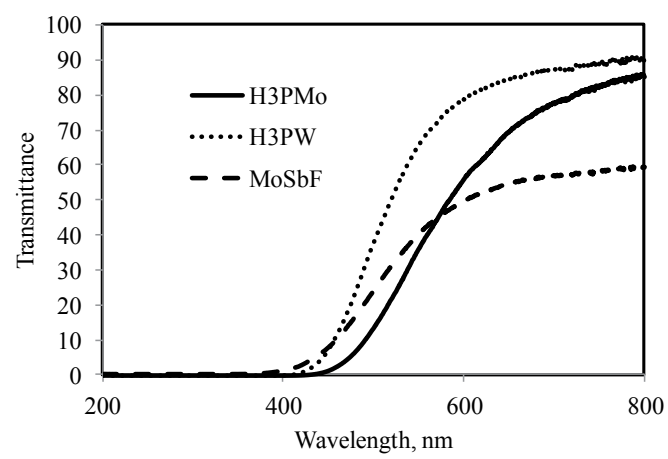

Figure 11: UV transmittance spectra of three solid cokes.

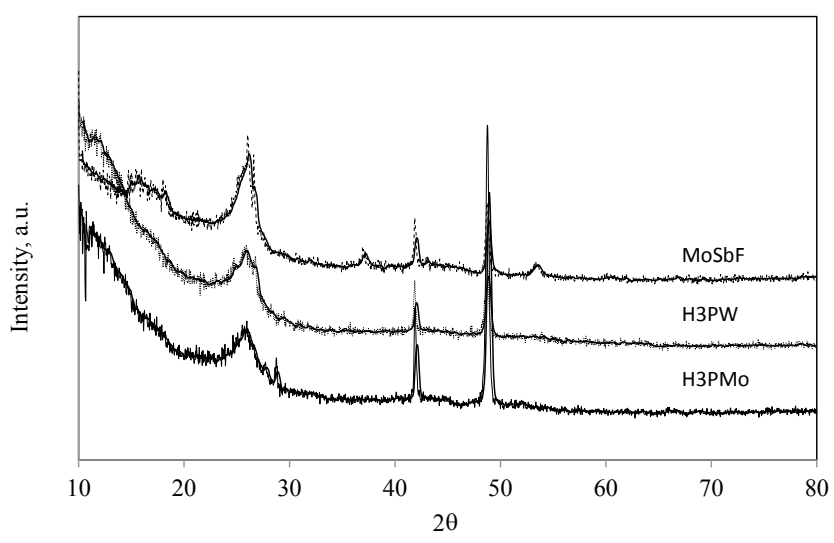

Figure 12: XRD diffractograms of three solid cokes.

$\mathrm{H}_{3} \mathrm{PW}$ is the hardest. The hardness property of a coke produced during hydrotreating reaction has been investigated in detailed by Beagon et al. [29] and Maity et al. [4,21]. As mentioned above that $\mathrm{H}_{3} \mathrm{PW}$ catalyst is comparatively effective for deep residue cracking and it may also lead to deep polymerization reaction for the formation of coke. As a result, formation of condensed polyaromatic structure in coke is a possible explanation for the hardness property of this coke. If coke $\left(\mathrm{H}_{3} \mathrm{PW}\right)$ is higher condensed, $\mathrm{H} / \mathrm{C}$ ratio should be lower. However, the $\mathrm{H} / \mathrm{C}$ in this coke is slightly higher than that of cokes produced by other two catalysts. It is observed above that thiophenic sulphur compounds are produced during cracking of residue in the presence of $\mathrm{H}_{3} \mathrm{PW}$ catalyst. During cracking reaction, C-S bond (presence in branching of condensed aromatic rings) cleavage occurs and $\mathrm{C}-\mathrm{H}$ bond is formed. This may be a possible explanation for having slightly higher $\mathrm{H} / \mathrm{C}$ ratio.

The nature of coke formed during reaction is also characterised by solid UV. The coke in general is UV inactive and that why most of the radiations pass through the coke. Around $90 \%$ of UV radiations (Figure 11) pass through the coke obtained by $\mathrm{H}_{3} \mathrm{PW}$ where as the transmittance is shifted to higher wavelength region for the coke obtained by other two catalysts. Therefore, the results indicate that the hard coke transmits more UV ray.

The crystalline nature of coke and metals were examined by XRD analysis (Figure 12). In the MoSbF and $\mathrm{H}_{3} \mathrm{PMo}, \mathrm{MoS}_{2}(2 \mathrm{H})$ peak is observed at $2 \Theta=14.44(002)$ (JCPDS data file 77-1716), and $\mathrm{WO}_{3}$ peak appears at 36.91 (002) and 53.35 (222) (JCPDS data file 01-072-1465). The presence of graphitic carbon in all three coke samples is confirmed by $2 \Theta$ at 26.03 in the XRD diffractogram.

\section{Conclusion}

Heteropoly acid of phosphomolybdic, phosphotungstic and superacid of molybdenum antimony super acids are synthesized and their hydrocracking activities were studied on vacuum residue. Tungsten containing catalyst shows higher HDM, HDAs and residue conversion activities. It is believed that this is due to the higher hydrogenation activity of tungsten. HDS activity of phosphomolybdic acid is high. It is also observed that all three catalysts show considerable hydrocracking activity at moderate operating conditions. It is also noticed from sulphur distribution of liquid product that due to C-S bond cleavage at branching of condensed aromatic rings, thiophenic sulphur compounds are formed. Moreover, phosphotungstic acid gives high percentage of aromatic products whereas the considerable amount of saturate hydrocarbons is produced by phosphomolybdic acid. The coke produced by $\mathrm{H}_{3} \mathrm{PW}$ catalyst is hard in nature indicating that extensive polymerization reaction at reaction conditions. Higher $\mathrm{H} / \mathrm{C}$ ratio indicates the deep hydrogenation of liquid products in presence of super acids. Phosphotungstic heteropoly acid could be useful for hydrocracking of residue instead of use superacid.

\section{References}

1. Furimsky E, Massoth FE (1999) Deactivation of hydroprocessing catalysts. Catal. Today 52: 381-495.

2. Maity SK, Perez VH, Ancheyta J, Rana MS, Centeno G (2007) Effect of asphaltene contained in feed on deactivation of Maya crude hydrotreating catalysts. Petroleum Science and Technology 25: 241-249.

3. Rana MS, Ancheyta J, Sahoo SK, Rayo P (2014) Carbon and metal deposition during the hydroprocessing of Maya crude oil. Catal Today 220-222: 97-105.

4. Maity SK, Blanco E, Ancheyta J, Alonso F, Fukuyama H (2012) Early stage deactivation of heavy crude oil hydroprocessing catalysts Fuel 100: 17-23.

5. Rayo P, Ramirez J, Torres-Mancera P, Marroquin G, Maity SK, et al. (2012) Hydrodesulfurisation and hydrocraking of Maya crude with P-modified NiMo$\mathrm{Al}_{2} \mathrm{O}_{3}$. Fuel 100: 34-42.

6. Eoma HJ, Lee DW, Kim S, Chung SH, Hur YG, et al. (2014) Hydrocracking of extra-heavy oil using Cs-exchanged phosphotungstic acid $\left(\mathrm{Cs}_{x} \mathrm{H}_{3-}\right.$ ${ }_{x} \mathrm{PW}_{12} \mathrm{O}_{40}, \mathrm{x}=1-3$ ) catalysts. Fuel 126: 263-270.

7. Olah GA, Bruce MR, Edelson EH, Husain A (1984) Catalysed depolymerizationionic hydroliquefaction of coals under mild conditions. Fuel 63: 1130-1137.

8. Olah GA, Husain A (1984) Superacid coal chemistry 2. Model compound studies under conditions of HF: BF: $\mathrm{H}$ catalysed mild coal liquefaction. Fuel 63: 1427-1431.

9. Olah GA, Bruce MR, Edelson EH, Husain A (1984) Superacid coal chemistry 3. Electrophilic substitution of coals under 'stable ion' conditions and the conversion of functionalized coals with the HF: BF: $\mathrm{H}$, liquefaction system. Fuel 63: $1432-1435$.

10. Siskin M, Wristers JP, Purcelli JJ (1975) Catalytic hydrocracking with a mixture of metal halide and anhydrous protonic acid. USA Patent 3: 901-790.

11. Ignasiak T, Bimer J, Samman N, Montgomery DS, Suausz OP (1981) In chemistry of asphaltenes, Advances in Chemistry Series 195, Bunger, JW, Li NC, (eds.), American Chemical Society, Washington, DC.

12. Strausz OP, Mojelsky TW, Payzant JD, Olah GA, Surya Prakash GK (1999) Upgrading of Alberta's heavy oils by superacid-satalyzed hydrocracking. Energy \& Fuels 13: 558-569.

13. Wen MY, Wender I, John W (1990) Hydroisomerization and hydrocracking of n-heptane and n-hexadecane on solid superacids. Energy \& Fuels 4: 372-379.

14. Magnotta VL, Gates BC (1977) Superacid polymers: Paraffin isomerization and cracking in the presence of $\mathrm{AlCl}_{3}$-sulfonic acid resin complexes. J Catal 46: 266-274.

15. Dooley KM, Gates BC (1985) Paraffin isomerization catalyzed by polymersupported superacids. J Catal 96: 347-356.

16. Imamura H, Soga K, Sato M, Wallace WE (1980) n-Pentane isomerization with 
Citation: Prajapati R, Kohli K, Maity SK, Garg MO (2016) Slurry Phase Hydrocracking of Residue by Phosphomolybdic and Phosphotungstic Acids. J Pet Environ Biotechnol 7: 281. doi:10.4172/2157-7463.1000281

Page 7 of 7

catalysts formed from brominated intermetallic compounds. Chem Lett 64: 957 958

17. Imamura H, Kato YT, Suchiya S (1984) Pentane isomerization activity of halogenated rare earth intermetallics. Bull Chem SOCJ pn. 57: 2309-2310

18. Imamura $\mathrm{H}$, Wallace WE (1980) $n$-Pentane isomerization with catalysts formed from brominated intermetallic compounds. J Catal 64: 238-239.

19. Hattori H, Takahaski IO, Takagi M, Tanabe K (1981) Solid super acids: preparation and their catalytic activities for reaction of alkanes. J Catal 68: 132-143.

20. Millan M, Adell C, Hinojosa C, Herod AA, Dugwell D, et al. (2007) Comparison of fractionation methods for the structural characterization of Petroleum residues. Energy \& Fuels 21: 1370-1378.

21. Kohli K, Prajapati R, Maity SK, Sau M, Garg MO (2016) Deactivation of hydrotreating catalysts by metals in resin and asphaltene parts of heavy oil and residue. Fuel 175: 264-273.

22. Okuhara $T$ (1996) Catalytic chemistry of Heteropoly compounds. Advances in Catalysis 41: 113-252.

23. Wang W, Yang SJ (2010) Photocatalytic degradation of organic dye methy orange with Phosphotungstic acid. Water Resource and Protection 2: 979-983.

24. Gachet G, Breysse M, Cattenot M, Decamp T, Frety R, et al. (1988) Optimization of the composition of Ni-W/A $1_{2} \mathrm{O}_{3}$ hydrotreating catalysts using model molecules and real feedstock conversion studies. Catal. Today 4: 7.

25. Reinhoudt HR, Troost $R$, van Langeveld $A D$, Sie ST, van Veen JAR, et al. (1999) Catalysts for second-stage deep hydrodesulfurisation of gas oils. Fuel Process Technol 61: 133-147.

26. Robinson WRAM, Van Veen JAR, De Beer VHJ, Van Santen RA (1999) Development of deep hydrodesulfurization catalysts: II. NiW, Pt and Pd catalysts tested with (substituted) dibenzothiophene. Fuel Process Technol 61: 103.

27. Bellamy LJ (1961) The Infrared spectra of complex molecules, (2ndedn), John Wiley \& Sons, New York.

28. AlHumaidan FS, Hauser A, Rana MS, Lababidi HMS (2016) Impact of therma treatment on Asphaltene functional groups. Energy \& Fuels 30: 2892-2903.

29. Begon V, Warrington SB, Megaritis A, Charsiey EL, Kandiyoti R (1999) Composition of carbonaceous deposits and catalyst deactivation in the early stages of the hydrocracking of a coal extract. Fuel 78: 681. 